\title{
Digital Storytelling and Mathematical Thinking: An Educational Psychology Embrace
}

\author{
Giuseppina Marsico ${ }^{\mathrm{a}}$, Monica Mollo ${ }^{\mathrm{a}}$, Giovannina Albano ${ }^{\mathrm{a}}$ Anna Pierri ${ }^{\mathrm{a}}$ \\ Corresponding author: Giuseppina Marsico (gmarsico@unisa.it) \\ ${ }^{a}$ University of Salerno (Italy)
}

Keywords: digital storytelling, educational psychology, mathematics, engagement, art

\begin{abstract}
This article proposes Digital Storytelling as an education model that combines science, narrative thinking and art. This model has been implemented in Italian school settings over recent years. After a short introduction of the theoretical foundations of narrative thinking in the history of Educational Psychology, the paper focuses on Digital Storytelling as a co-constructive educational method that uses digital technologies for promoting an active, situated, meaningful and reflexive learning process. The proposed intervention in the Italian settings adds the artistic digital component (the use of avatar, comics and science fiction) to the Digital Storytelling systems. The set of implemented activities, as well as the individual and group actions taken, promote both the cognitive and emotional aspects of the learning process. The findings show that Digital Storytelling, spiced with artistic features, prompts the engagement of students in learning activities and offers a platform to enhance behavioural, emotional and cognitive commitment in mathematics education.
\end{abstract}

\section{Introduction}

Digital Storytelling (DST) is the present-day version of the ancient practice of telling stories. According to Bruner (1986) there are two complementary modes of thought: the paradigmatic and the narrative. They organise experience in different ways, as they use distinct rationales to establish causality, to persuade, to verify truth. The mode of thinking is the epistemological foundation of Digital Storytelling that makes use of various types of media: hypertext, pictures, sounds, movies etc. and that has been successfully applied in the educational field in recent years. A story problem can be seen as a mathematical problem that has been contextualised in concrete and realistic situations. A key issue for storytelling to be a powerful means to mediate mathematical problem solving is the correct balance between narratively relevant and logically relevant kinds of information. This requires careful design of the story from which the mathematical problem should naturally arise. Thus, DST allows the development of skills in meaningful and engaging contexts integrating logical thinking and narrative thinking via artistic means. This article aims to present how the artistic features and educational potential of DST has been applied in a research project in Italian schools. In the following pages, the theoretical background of narrative thinking will be discussed, then the digital and artistic components of DST in supporting the mathematical reasoning will be illustrated, and finally some of the main findings of an Italian project in Digital Interactive Storytelling in Mathematics will be illustrated.

\section{Narrative thinking}

Storytelling, in all its forms (oral, written or visual), is the oldest mean of communication. It is at the core of any process of making meaning in our ordinary lives and it is a tool for generating 
understanding in an intersubjective and culturally situated manner. Stories provide the circumstantial, real life settings that allow people to know how things may be. According to Bruner (2012):

The easiest and natural way we organize things is in a story-telling mode. How is it that the Earth goes around the sun and we tell a story about something called gravitational forces? Then we converted into something paradigmatic, something that can be translated into a more formal scientific mode, but there is some interesting kind of relationship between the narrative mode of telling the story part and paradigmatic modes (p. 27-28).

Narrative and paradigmatic are, indeed, modes of knowing and communicating. Both are crucial for the knowledge building process and psychologically very complex. However, while the epistemological principles (i.e. linearity, formal causality, truth/falsehood criteria etc.) of the paradigmatic way of knowing has been widely investigated, the complexity of the narrative thinking and its potential in the educational setting has been overlooked (Marsico, 2017).

\section{What is narrative thinking about?}

Narrative is a kind of discourse to report events in oral, written, and visual language. Those discursive activities (i.e. speaking, writing, visual expressions) are not merely means for expressing our thoughts, but they give form to and develop our thinking. The role of any form of narrative in the cognitive realm is therefore much more complex than it apparently seems. We, as humans, construct our reality and our psychological functioning through narratives (Marsico, 2015). That is why narratives have not only to do with narrated fact, but with how 'we make ourselves' and how we construct our world. In Bruner's words:

It has to do with the nature of thought and with one of its uses. It has been traditional to treat thought, so to speak, as an instrument of reason. Good thought is right reason, and its efficacy is measured against the laws of logic or induction. Indeed, in its most recent computational form, it is a view of thought that has sped some of its enthusiasts to the belief that all thought is reducible to machine computability. But logical thought is not the only or even the most ubiquitous mode of thought. For the last several years, I have been looking at another kind of thought (see, e.g., Bruner, 1986), one that is quite different in form from reasoning: the form of thought that goes into the construction not of logical or inductive arguments but of stories or narratives (Bruner, 2004, p.691).

Narratives are general and particular at the same time. They seem to be universal, but they always develop in specific cultural contexts and even when they refer to collective phenomena apparently beyond the uniqueness of the individual's life, the narratives express the subjective point of view regarding the flux of events as well as the personal positioning toward them. Exemplification and generalisation are the two indisputable cognitive processes involved in telling a story. This makes storytelling a powerful means for educational purposes, since it combines the concreteness of specific learning situations with the generalizability and transferability of knowledge.

The relevance of storytelling as an educational tool has recently received increasing interest in both the humanities and science disciplines (Salmon, 2007; Schiro, 2017; Wickmann \& Ostman, 2002) because it allows: a) to link (as mentioned above) abstract information into concrete situations and vice versa and b) to promote an affective platform for a psychological identification/closeness with the characters as well as the process of engagement. 
As we will discuss in the next pages both the process of identification and the engagement are the main issues fostered by the use of storytelling in a mathematical education project we are developing in an Italian educational context. In addition, the use of artistic components integrated with the advances in technology has taken the form of digital storytelling that seems to be closer to younger generations' ordinary languages and helps the engagement process in mathematical thinking.

\section{Digital storytelling}

Digital Storytelling (DST) is the modern version of the ancient practice of telling stories, making use of various types of media: hypertext, pictures, sounds, movies and so on. From the very beginning, storytelling has been used as a fundamental method of knowledge transfer. In teaching, it makes the learning environment more enjoyable and knowledge more accessible, because students are more involved in learning processes. Its power is to engage students on the non-cognitive level of emotion and imagination. Many studies show the benefits of DST in education, both for teachers and students (Sadik, 2008; Robin, 2008), also in mathematics (Albano \& Pierri, 2017; Starcic, Cotic, Solomonides, \& Volk, 2015; Gould \& Schmidt, 2010; Inan, 2015; Petrucco, Mattioli, \& Loi 2010; Ravanelli, 2012).

Among these we highlight the modern approach to learning by competencies, overcoming the knowledge/skills dichotomy. In mathematics, DST allows the development of skills in real, meaningful and engaging contexts (Jonassen, 2003; Schiro, 2004) as well as the integration of logical thinking and narrative thinking. If well calibrated, story problems can be very effective in mathematics education (Zan, 2011). Story problems are those in which the mathematical structure is put into a familiar situation for the student and takes the form of a narrative. In order to understand the story, the student has to resort not only to logical thinking, which is used to explain the things that happen using deductive logic, but also to narrative thinking, which is concerned with giving meaning to things, thus bringing into play intentions, desires, beliefs and feelings (Bruner, 1986). For a story to support the process of resolution, the narrative and logical dimensions must be well integrated (Zan, 2012). In order to modulate the two dimensions of the textual problem, so that the solution of the problem is supported, Zan (2012) suggests the so-called C\&Q model (context and question), characterized by the following points:

- There is a story: temporal evolution of a situation, at least one animated character;

- There is a natural connection between history and question: a character with a purpose and context from which the mathematical problem arises in a natural way;

- The story is well structured: the parts of the text are linked together, the information has a 'narrative' meaning.

Zan underlines the importance of the question arising naturally from the need to reach a goal for the character of the story and, for it to make sense, this goal has not yet been achieved; that is, the student must be able to imagine being able to affect the story with its resolution.

The benefit of bringing storytelling into a mathematics classroom is the ability to introduce or explain hard concepts in a memorable fashion and involve students in a mathematical activity. Thus, a story problem could be conceived as a mathematical problem which has been contextualised in concrete and realistic situations, familiar to the student with respect to their life experiences. In the representation stage the students' knowledge should be the basis of the solution. This story-centered curriculum allows teachers to overcome the major limits of the current styles of math education by promoting a situated thinking, dialogical and argumentative competencies, and the capability to generalize the acquired knowledge beyond the school settings. 


\section{Methods}

\section{The considered theoretical framework}

For the design of the educational activities, we placed ourselves in the context of Vygotskian didactics (Vygotsky, 1978), where learning is first socialised and then internalised. In this context, we have mainly referred to the Activity Theory (Leont'ev, 1978) and to collaborative learning, in particular computer-based learning.

The Activity Theory is an approach, developed in the field of psychology and of the social sciences, which studies individuals on the basis of an analysis of their activity. The key concept is therefore that of activity, which is understood as something characterized by interaction - an action in the world, and intentionality - the action serves a purpose. The activity is a construct of high level, usually collaborative. It can be placed at the top of a hierarchy, together with two further components: actions and operations, which are identified respectively by awareness (to have an objective), and by unawareness (function).

\section{Methodology: The artistic component}

The learning will then develop through the involvement of the student in appropriate educational activities that take place within a narrative, in a situation that may be engaging and familiar to the student. So, we imagined a set of activities that the student should explore also by comparing with a group of friends.

The project involved two first year classes of 24 and 28 students of two different high schools. In each class, the students were divided into groups of four members. In this way, we had six and seven groups respectively. The collaborative group encompasses a number of predetermined roles, each of them devoted to a given disciplinary function (Pesci, 2004) such as: task-oriented, responsible for all actions oriented to achieve the best result; group-oriented, responsible for the communication mode within the group; speaker, spokesperson, to speak on behalf of the group about all proposals; memory, responsible for saving a written recording of the achieved results; and observer, responsible for observing all group interactions. Subsequently, a new role, born in the context of an inquiry approach (Arzarello \& Soldano, 2016) has been added to the initial set, listed above, which we called the Devil's advocate, i.e. a person who asks questions about what his/her classmates propose or say, and insinuates doubts. Moreover, since the story makes use of technological tools, we have envisaged a new role, i.e. technology-oriented, able to support the teammates and to help them overcome possible problems arising from the use of technological tools.

So, each student has a role and actions to perform, sometimes alone, sometimes together with others. The role, functional to the success of learning, must be contextualised within the story. The personal and group interaction will change the evolution of the story.

The kind of story chosen is that of science fiction, which sees a group of four friends engaged in the enterprise of communicating with aliens from whom they have received mysterious messages made of numbers and operations. Our four friends correspond to the four roles provided: group-oriented, speaker, devil's lawyer and technology-oriented, which all have been appropriately contextualised within the story as characters' profile:

- Marco, called 'the BOSS' (i.e. the group-oriented), is the leader within the group of friends, and has won the trust of his teammates for his leadership behaviours; 
- Sofia is passionate about reading and writing and she hopes to become a journalist and has got a craze for blogging. In fact, she is called 'the BLOGGER (i.e. the group-oriented);

- Clara is a wary girl and constantly pesters her classmates with doubts and questions...she is 'the PEST'(i.e. the Devil's advocate);

- Federico is a computer enthusiast, convinced of the existence of extra-terrestrial lives, he is always fiddling with electronic devices in search of alien signals. That is why he is called 'the COMPUTER GEEK', (i.e. the technology-oriented).

Figure 1 shows the four avatars that have been created to reflect as closely as possible the characteristics of the character they represent in the story. For example, if we look to the Clara avatar (the fourth image shown in the Figure 1), we observe that she has a hairstyle and clothing that reflects very much her role.

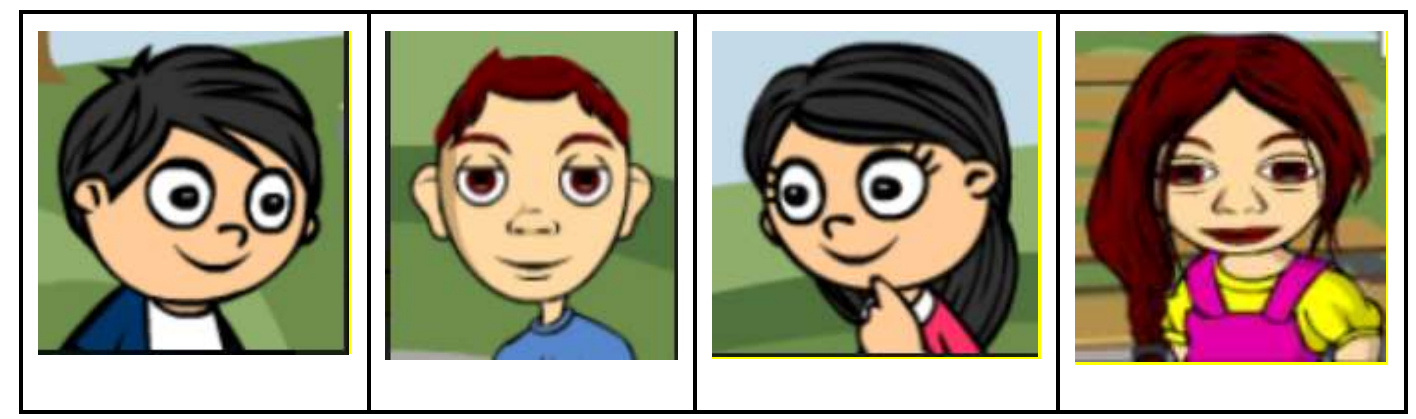

\section{Figure 1: The four avatars}

There is also a tutor, known as the expert, who acts according to the Vygotskian approach (Vygotsky, 1978), and supervises and supports the work of the students for learning to be successful. In the context of the story, this role is covered by a specific character, Gianmaria, identified as Federico's uncle, an expert himself in computer devices and a lover of mathematics, (see Figure 2).

\section{Figure 2: Gianmaria's avatar}

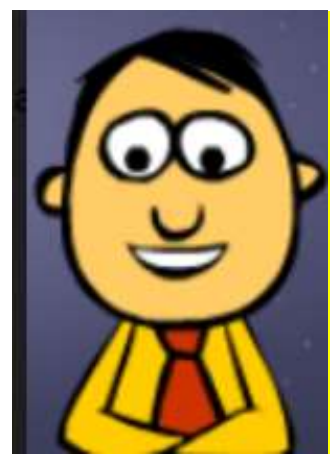

The creation of the comics has been realised through the software ToonDoo (www. toondoo.com), the use of which is possible after registration.

To start creating a comic you must choose the layout you want to use. From here, you can select the type of background and its characters, protagonists of the story. We used the tool 'capture image' to take the comic from ToonDoo and save it in a powerpoint presentation where we inserted the text of the comics by callout. 


\section{Findings: Getting involved into the story}

The following excerpts show how the students have identified themselves in the character as depicted by the roles:

Micheleo acts as the boss, who has to worry about managing the group and making sure that everyone is involved.

\section{4:12 micheleo:}

ragazzi però cercate di parlare tutti sennò non riusciamo mai ad andare avanti. se ora non potete magari connettetevi appena potete e dite cosa ne pensate

English translation:

Guys, try to talk all otherwise we can never move forward. If you cannot now, maybe connect as soon as you can and say what you think about it

Danieler acts as a pest, since she reviews with a critical eye what the classmates say and intervenes to highlight if what has been said does not work.

\section{1:58 katiam: \\ si deve fare più \\ 9}

\section{1:58 danieler:}

si ma l'ultimo numero è 5 della prima colonna quindi non può essere

English translation:

katiam: you have to add 9

danieler: yes, but the last number is 5 in the first column so it can't be

Some further excerpts refer to the engagement in the storytelling. Mathematics is left aside and the information obtained is reinterpreted in the context of the story told, such as in the case below.

\section{1:54 danieler:}

Ma i vari risultati che ricaviamo dai vari calcoli non poitrebbero essere delle coordinate geografiche???

English translation

Couldn't the various results we get from the various calculations be geographical coordinates??? 
As the above examples clearly show, the DST provides an immersive learning experience. The students are not merely listeners. They interact with the story by entering in the plot and their contribution influences the course of the story itself.

\section{Discussion: when Digital Storytelling prompts engagement}

So far, the general methodology, the main guidelines as well as the artistic, pedagogical and mathematics education principles chosen for designing the educational activities have been discussed. The focus will now be on the general components and the psychological process that make the Digital Storytelling an extraordinary means to promote effective mathematical learning in the classroom.

We live in a globalized world permeated by various kinds of hypermedia that are increasingly accessible and affordable (becoming part of our everyday life). This is especially true for the younger generations born into a digital world. School, then, cannot be detached from the real life and the teaching-learning process must capitalise on technological innovations in a meaningful manner. Digital Storytelling represents a powerful tool to engage students in learning activities. It provides both the support and the structure (Jang, Reeve, \& Deci, 2010) for the student to experience the 'spark of excitement' that stems from discovery (Tytler, 2007).

Digital Storytelling has its own epistemological roots in one of the most fundamental theoretical turns in cognitive psychology of the recent time: the so called narrative turn (Bruner, 1986, 1991, 2001, 2004, 2012). This has, as its core, the idea that "world making' is the principal function of mind, whether in the sciences or in the arts" (Bruner, 2004, p. 691). Digital Storytelling, 'makes use' of the psychological principles of the narrative way of knowledge production to reach specific academic goals.

According to Zan, in fact, narrative thinking "leads to good stories, gripping drama, believable (though not necessarily 'true') historical accounts [and] deals in human or human-like intention and actions and the vicissitudes and consequences that mark their courses" (2011, pp. 11-13). In this context, there will be information relevant for understanding the problem defined narratively relevant, and information relevant for the problem solving process, called logically relevant. Both are the pillars in designing a storytelling task in a math class.

In addition, Digital Storytelling is usually based on the integration of different types of media, visual art and other technological resource. In our project, we introduced an important additional artistic component: the comics which promote the student-character psychological identifications. Science fiction is, then, the frame that makes possible the student engagement in a meaning-making process and in a problem solving task. Students' engagement results, then, the ultimate psychological process activated by the Digital Storytelling as we have designed and implemented it.

It is a given that student's engagement is a widespread problem in the school. The key psychological concept to understand engagement is the notion of intrinsic motivation (Ryan \& Deci, 2009) that implies, among other things, feelings of self-determination and of competence, expectations of success, as well as a sense of interpersonal relatedness. By acknowledging these main axis in the human intrinsic motivation, the school should propose opportunities for positive learning. Digital Storytelling, spiced with artistic features, seems to offer the platform to enhance behavioural, emotional and cognitive engagement in the mathematical education. 


\section{Acknowledgment}

This research is funded by the Italian Ministry of Education, University and Research within the Research Project of National Interest (PRIN) "Digital Interactive Storytelling in Mathematics: a competence-based social approach", PRIN2015, Prot. 20155NPRA5

\section{References}

Albano, G., \& Pierri, A. (2017). Digital storytelling in mathematics: A competence-based methodology. Journal of Ambient Intelligence and Humanized Computing, Vol. 8, pp. 301-312.

Arzarello F, \& Soldano C. (2016) Da Peirce a Hintikka (senza dimenticare Dewey): la logica dell'indagine in classe. In: F. Morselli, G. Rosolini, C. Toffalori (eds), Educare alla razionalità. In ricordo di Paolo Gentilini, Atti del Convegno di Sestri Levante 9-11 Giugno 2016.

Bruner, J. S. (1986). Actual minds, possible worlds. Cambridge and London: Harvard University Press.

Bruner, J., S., (1991). The narrative construction of reality. Critical Inquiry, 18(1), p. 1-21.

Bruner, J. (2001). Self-making and world making. In J. Brockmeier \& D. Carbaugh (Eds.), Narrative and identity: Studies in autobiography, self and culture (pp. 25-37). Amsterdam/Philadelphia: John Benjamins Publishing Company.

Bruner, J. (2004). Life as narrative. Social Research, 54, 691-710.

Bruner, J., S. (2012). Cultivating the possible. LERNing Landscape, Vol.5, n.2, 27-33.

Gould, D., \& Schmidt, D. A. (2010). Trigonometry comes alive through Digital Storytelling. Mathematics Teacher, v. 104, n., 296-301.

Inan, C. (2015). A digital storytelling study project on mathematics course with preschool pre-service teachers. Educational Research and Reviews, Vol. 10(10), 1476-1479.

Jang, H., Reeve, J., \& Deci, E. L. (2010). Engaging students in learning activities: It is not autonomy support or structure but autonomy support and structure. Journal of Educational Psychology, 102(3), 588-600. http://dx.doi.org/10.1037/a0019682

Jonassen, D. H. (2003). Designing research-based instruction for story problems. Educational Psychology Review, 15(3), 267-296.

Leont'ev, A.N. (1978). Activity, consciousness, and personality. Englewood Cliffs: Prentice-Hall.

Marsico, G., (Ed). (2015). Jerome S. Bruner beyond 100. Cultivating possibilities. Cultural Psychology of Education, 2, Cham, Switzerland: Springer;

Marsico, G., (2017). Jerome S. Bruner: Manifesto for the future of education, Infancia y Aprendizaje, Journal for the Study of Education and Development, 40(4), 754-781, DOI: 10.1080/02103702.2017.1367597;

Pesci, A., (2004). Insegnare e apprendere cooperando: esperienze e prospettive, L'insegnamento della matematica e delle scienze integrate, Vol. 27 A-B n. 6, 637-670

Petrucco, C., Mattioli, M., \& Loi O. (2010). Una esperienza di Digital Storytelling sulla didattica della matematica. Atti del convegno Didamatica 2010.

Ravanelli, F. (2012). Una esperienza di Matematica e Digital Storytelling nella scuola primaria. Bricks. Anno 2, n. 4.

Ryan, R. M., \& Deci, E. L. (2009). Promoting self-determined school engagement: Motivation, learning, and well-being. In K. R. Wentzel \& A. Wigfield (Eds.), Handbook on motivation at school (pp. 171-196). New York: Routledge.

Robin, B. (2008). The effective uses of digital storytelling as a teaching and learning tool. Handbook of research on teaching literacy through the communicative and visual arts (Vol. 2). New York: Lawrence Erlbaum Associates.

Sadik, A. (2008). Digital storytelling: A meaningful integrated approach for engaged student learning. Educational Technology Research, (56), 487-506.

Schiro, M. (2004). Oral storytelling and teaching mathematics. Thousand Oaks, CA: SAGE Publications.

Salmon, C. (2007). Storytelling: la machine à fabriquer des histoires et à formater les esprits. Paris: La Découverte,

Schiro, M.S. (2004). Oral storytelling and mathematics. London: Sage Publications

Starcic, A. I., Cotic, M., Solomonides, I., \& Volk M. (2015). Engaging preservice primary and preprimary school teachers in digital storytelling for the teaching and learning of mathematics. British Journal of Educational Technology - doi: 10.1111/bjet.12253.

Tytler. R. (2007). Re-imagine science education. Engaging students in Science, for Australia's future. Victoria: ACER Press.

Vygotsky, L. S. (1978). Mind in society: The development of higher psychological processes. US: Harvard University Press. 
Wickmann, P.-O., \& Ostman, L. (2002). Learning as discourse change: A sociocultural mechanism. Science Education, 86, 601-623.

Zan, R. (2011). The crucial role of narrative thought in understanding story problems. In Current State of Research on Mathematical Beliefs XVI. Proc. of MAVI 16 (Tallinn), p. 287-305.

Zan, R. (2012). La dimensione narrativa di un problema: il modello C\&D per l'analisi e la (ri)formulazione del testo. Parte I. L'insegnamento della matematica e delle scienze integrate. Vol.35 A N.2 marzo 2012. 